\title{
Fire Environment in Partially Vented Automobile Crash Fires
}

\author{
A. TEWARSON \\ FM Global \\ 1151 Boston-Providence Turnpike \\ Norwood, MA 02062, USA
}

\begin{abstract}
Data from eleven vehicle burn tests, measured in the passenger compartment and in the fire plume, have been analyzed. In the analysis, measured ratios of release rates of heat and products and concentrations and heat of combustion and product yield ratios from the literature have been used. The analysis shows that conditions are close to stoichiometric combustion inside the passenger compartment and in the plume just before time to untenable/flashover conditions. The times to untenable/flashover conditions are in the range of 155 to 300 seconds for fires started in the rear of the vehicle and in the range of 645 to 1620 seconds for fires started in the front of the vehicle. Most of the time to untenable/flashover conditions is due to time taken by flames to enter the passenger compartment.

In the vehicle fires, higher amount of fuel is converted to $\mathrm{CO}$ rather than to smoke under fuel-rich conditions. Relative contributions of the nitrogen and non-nitrogen containing fuels in vehicle fires is assessed from the ratio of HCN to CO concentrations. The analysis suggests that it is possible to model vehicle fires and assess the survivability of passenger through modifications to the vehicle and its polymer parts.
\end{abstract}

KEYWORDS: automobile crash fires, transportation fires, compartment fires, fire environment, untenable/flashover conditions, release rates of heat and fire products

NOMENCLATURE LISTING

\begin{tabular}{|l|l|l|l|}
\hline$A$ & Surface area of the fuel $\left(\mathrm{m}^{2}\right)$ & $V_{\text {fire }}$ & Fire growth rate $(\mathrm{kW} / \mathrm{s})$ \\
\hline$C_{j}$ & Concentration of product j $(\mathrm{ppm})$ & $y_{j}$ & Yield of product j (g/g) \\
\hline$f_{j}$ & Generation efficiency & Greek \\
\hline$\dot{G}_{j}$ & Release rate of a product $(\mathrm{g} / \mathrm{s})$ & $\chi$ & Combustion efficiency \\
\hline$\Delta H_{c h}$ & Heat of combustion $(\mathrm{kJ} / \mathrm{g})$ & $\eta$ & Product generation efficiency \\
\hline$\Delta H_{q}$ & Heat of gasification $(\mathrm{kJ} / \mathrm{g})$ & $\rho$ & Density $\left(\mathrm{g} / \mathrm{m}^{3}\right)$ \\
\hline$\Delta H_{T}$ & heat of complete combustion $(\mathrm{kJ} / \mathrm{g})$ & $\Phi$ & Equivalence ratio \\
\hline$\dot{m}_{f}^{\prime \prime}$ & Release rate of fuel vapors $\left(\mathrm{g} / \mathrm{m}^{2}-\mathrm{s}\right)$ & $\Psi_{j}$ & Maximum possible yield \\
\hline$\dot{m}_{a}$ & Mass flow rate of air (g/s) & Subscripts \\
\hline$M_{j}$ & Molecular weight (g/mole) & $a$ & Air \\
\hline$\dot{q}_{i}^{\prime \prime}$ & Heat flux (kW/m $\left.{ }^{2}\right)$ & $e$ & External \\
\hline$\dot{Q}_{c h}$ & Heat release rate (kW) & $f$ & Flame \\
\hline$s$ & Stoichiometric fuel-to-air ratio (g/g) & $r r$ & Re-radiation \\
\hline$t_{p i}$ & Time post ignition (s) & $s m$ & Smoke \\
\hline$t_{u, f l}$ & Time to untenable/flashover (s) & \multicolumn{2}{|l|}{} \\
\hline
\end{tabular}




\section{INTRODUCTION}

In enclosure fires, unburned materials and products are vented naturally or forcibly. The natural and forcible venting of fire depends on the fire size and on the size and location of openings, which govern the airflow into the enclosure. In general, for large openings, two zones are formed inside the enclosure, an upper zone, and a lower zone. The upper zone is fuel rich, where fuel partially burns with air and the partially burned fuel and products flow out of the enclosure naturally, whereas the lower zone consists of fuel pyrolyzate mixed with air that fills the upper zone. Many enclosure fire models use the two-zone concept. As the size of the opening decreases, the upper and lower zones merge and fuelrich region expands. As a result, the concentrations of products of incomplete combustion and unburned fuel pyrolyzate increase rapidly, mix with air and fire is forcibly vented out, which is defined as flashover.

In enclosure fires, especially in the large-scale tests, limited numbers of measurements are made, however, these measurements become useful when combined with the following expressions for release rates of heat and products and fuel properties from the literature:

1) Heat Release Rate, $\left(\dot{Q}_{c h}\right)$ :

$$
\dot{Q}_{c h}=\Delta H_{c h} \dot{m}_{f}=\left(\Delta H_{c h} / \Delta H_{g}\right)_{f}\left(\dot{q}_{f}^{\prime \prime}+\dot{q}_{e}^{\prime \prime}-\dot{q}_{r r}^{\prime \prime}\right) A
$$

where $\Delta \mathrm{H}_{\mathrm{ch}}$ is the heat of combustion, $\dot{\mathrm{m}}_{\mathrm{f}}$ is the release rate of fuel vapors, $\Delta H_{g}$ is the heat of gasification, $\dot{q}_{f}^{\prime \prime}$ is the flame heat flux to the fuel surface, $\dot{q}_{e}$ is the external heat

flux to the fuel surface, $\dot{q}_{r r}^{\prime \prime}$ is the surface re-radiation loss, and $A$ is the surface area of the fuel.

2) Release Rates of Products $\left(\dot{G}_{j}\right)$ :

$$
\dot{G}_{j}=C_{j}\left(\rho_{j} / \rho_{a}\right) \dot{m}_{a}=y_{j} \dot{m}_{f}=\left(y_{j} / \Delta H_{g}\right)\left(\dot{q}_{f}^{\prime \prime}+\dot{q}_{e}^{\prime \prime}-\dot{q}_{r r}\right) A
$$

where $C_{j}$ is the concentration of product $j, \dot{m}_{a}$ is the mass flow rate of air, $\rho_{j}$ and $\rho_{a}$ are the densities of product $j$ and air respectively and $y_{j}$ is the yield of product $j$. From the definitions of combustion efficiency $\left(\chi=\Delta H_{c h} / \Delta H_{T}\right.$ ), where $\Delta H_{T}$ is the net heat of complete combustion, product generation efficiency $\left(\eta_{j}=y_{j} / \Psi_{j}\right)$, where $\Psi_{j}$ is the maximum possible stoichiometric yield of a product (yield of the product if all the fuel carbon atom could be converted into the product in the combustion process).

The ratios of the release rates of heat and products in Eqs. 1 and 2 can be expressed as:

$$
\dot{G}_{j} / \dot{Q}_{c h}=y_{j} / \Delta H_{c h}=\left(\eta_{j} / \chi\right)\left(\Psi_{j} / \Delta H_{T}\right)=\left(\eta_{j} / \chi\right)\left(0.002 M_{j} / \Delta H_{T}\right)
$$




$$
\begin{aligned}
\dot{G}_{j 1} / \dot{G}_{j 2} & =y_{j 1} / y_{j 2}=\left(C_{j 1} / C_{j 2}\right)\left(\rho_{j 1} / \rho_{j 2}\right)=\left(\eta_{j 1} / \eta_{j 2}\right)\left(\Psi_{j 1} / \Psi_{j 2}\right) \\
& =\left(\eta_{j 1} / \eta_{j 2}\right)\left(M_{j 1} / M_{j 2}\right)
\end{aligned}
$$

where $\Delta H_{T}$ is the net heat of complete combustion and $M_{j}$ is the molecular weight of product $j$. Both $M_{j}$ and $\Delta H_{T}$ are the fundamental fuel properties. All the parameters that depend on the size, shape, arrangement, and heat flux drop out from Eqs. 3 and 4. where $\Delta H_{T}$ is the net heat of complete combustion and $M_{j}$ is the molecular weight of product $\mathrm{j}$. Both $M_{j}$ and $\Delta H_{T}$ are the fundamental fuel properties. All the parameters that depend on the size, shape, arrangement and heat flux drop out from Eqs. 3 and 4. In addition, the fuel property ratios, $\eta_{\mathrm{j}} / \chi$ and $\eta_{\mathrm{j} 1} / \eta_{\mathrm{j} 2}$ in these equations are independent of the size, shape, arrangement, and heat flux, but depend on the generic nature of the fuel and fuellean/fuel-rich conditions, as expressed by the equivalence ratio, $\Phi$ :

$\Phi=\left(\dot{m}_{f} / \dot{m}_{a}\right) / s$

where $s$ is the stoichiometric fuel-to-air ratio. For fuel-lean fires, $\Phi<1.0$, where combustion is independent of $\Phi$; for fuel-rich fires, $\Phi \geq 1.0$. For fuel-lean conditions, the ratios in Eqs. 3 and 4 are conserved and have unique values for each fuel; however, the ratios also depend on $\Phi$ for fuel-rich conditions. With increase in $\Phi$ and change in the nature of chemical bonds from aliphatic-saturated to unsaturated to aromatic to halogenated, the ratios of release rates of heat and products of complete combustion and their concentrations (such as $\mathrm{CO}_{2}$ ) decrease and release rates of products of incomplete combustion and their concentrations (such as CO, hydrocarbons, HCN, and smoke) increase.

In this paper, an attempt has been made to use Eqs. 3 to 5 to examine the data for the simultaneous combustion of variety of fuels in complex geometries in ventilation restricted small enclosures, such as from the vehicle burn tests [1]. The vehicle burn tests were performed to assess the passenger survivability in motor vehicle crash fires. The tests were sponsored by the General Motor Corporation (GM) under the U.S. DOT and GM agreement of 1995. Penetration of flames into the passenger compartment was the most critical stage in vehicle burn tests. Pain, $2^{\text {nd }}$ and $3^{\text {rd }}$ degree burns, flashover, toxicity, and lethality followed in that order very shortly after the flame penetrated the passenger compartment. Times to untenable conditions defined in terms of pain, $2^{\text {nd }}$ and $3^{\text {rd }}$ degree burns, derived from the "BURNSIM" model, and times to toxicity and lethality, derived from the FAA and Purser models [1]. Time to flashover was identified by the temperature recorded by bare thermocouples below the headliner centered in the vehicle, or by the array of aspirated thermocouples located below the headliner [1]. In most cases, this was based on a sudden increase in temperature or temperatures exceeding 400 to $500^{\circ} \mathrm{C}$ [1]. The flame penetration into the passenger compartment from the engine compartment fires in the front crashed vehicle burn tests was significantly longer (10 to 24 minutes post ignition) than from the gasoline pool fires under the vehicle in the rear crashed vehicle burn tests ( 0.5 to 3.0 minutes post ignition). Thus, mode of combustion in the passenger compartment is critical for the passenger survivability in the vehicle crash fires. 
In the vehicle burn tests, there is simultaneous combustion of solid and expanded polymer parts (in the passenger compartment under restricted ventilation), of fluids mixed with solid polymer parts (in the engine compartment, also under restricted ventilation), and of engine compartment fluids and gasoline as pool fires under the vehicle in the open. Furthermore, the unburned fuels vent out of the passenger and engine compartments and burn in the plume in the open above the vehicle.

Vehicle parts are made of hydrocarbon based aliphatic polymers, such as polyethylene (PE), polypropylene (PP), and nylon, aromatic polymers such as polystyrene (PS), polycarbonate (PC), acrylonitrile-butadiene-styrene (ABS) and expanded polyurethane foam, and halogenated polymers such as polyvinylchloride (PVC). However, majority of the solid fuel mass is mainly aliphatic in nature. Similarly, majority of the liquid fuel mass is mainly aliphatic in nature (gasoline, motor oil, transmission oil, power steering oil, lubricating oil, brake fluid, antifreeze, engine coolant and windshield washing fluid). Thus, in the vehicle burn tests, measured data are expected to be closer to the combustion data for the aliphatic fuels.

\section{VEHICLE BURN TESTS}

The vehicle burn tests were performed at FM Global under the Fire Products Collector (FPC), shown in Fig. 1 [1].

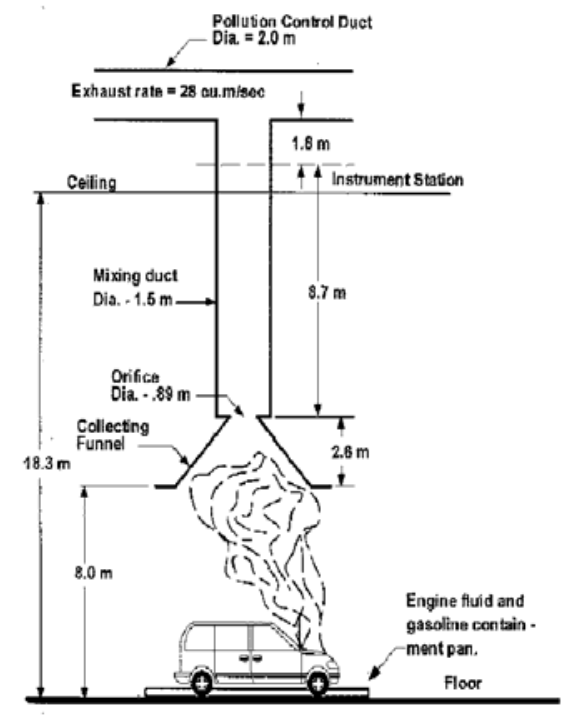

Fig. 1. Vehicle burn test under the Fire Products Collector.

It consisted of a fire products collection funnel (6.1-m in diameter with a 0.9-m diameter orifice plate) and a vertical stainless steel sampling duct (diameter of $1.5 \mathrm{~m}$ ). The sampling duct was connected to an air-pollution-control system. The blower of the airpollution-control system induced airflow through the sampling duct. Air entered the sampling duct via the orifice plate. 
In the tests, two vehicles from each of the following six models were used; one vehicle was crashed in the front and the other in the rear at the GM Proving Ground (test dates are included in the parenthesis [1):

1. 1996 Dodge Caravan (13-Nov-1996)-front crash and ignition;

2. 1996 Plymouth Voyager (15-Nov-1996)-rear crash and ignition;

3. 1997 Chevrolet Camaro (30-Sept-1997)-rear crash and ignition;

4. 1997 Chevrolet Camaro (01-Oct-1997)-front crash and ignition;

5. 1998 Ford Explorer (09-June-1998)-rear crash and ignition;

6. 1998 Ford Explorer (11-June-1998)- front crash and rear ignition;

7. 1998 Honda Accord (23-Feb-1999)-front crash and ignition

8. 1998 Honda Accord (25-Feb-1999)-rear crash and ignition;

9. 1999 Chevrolet Camaro-Control (17-Feb-2000)-front crash and ignition;

10. 1999 Chevrolet Camaro-FR HVAC (21-Feb-2000)- front crash and ignition;

11. 1999 Ford Explorer-underbody intumescent paint (23-Feb-2000)-front crash and rear ignition.

Each vehicle was placed in a 7.6-m long, 4.6-m wide and 0.10-m deep steel containment pan under the FPC. The pan was fabricated from two sheets of carbon steel. The bottom of the pan was lined with concrete landscaping paving blocks on a level bed of sand. The pan was placed on top of a lead cell. In each test, the vehicle was ignited inside the engine compartment or under the vehicle in the rear following the ignition scenarios observed in the front and rear crash tests. Fires in the front crashed vehicle tests were started in the engine compartment by electrical shorts or by the hot engine compartment fluids sprayed onto to hot metal surfaces. Fires in the rear-crashed vehicles were started under the vehicle by igniting gasoline that was allowed to leak slowly from the fuel tank into a pool in the rear.

After ignition, flames spread from the engine compartment or from the underbody of the vehicle to the passenger compartment. As soon as the flames entered the passenger compartment, untenable/flashover conditions were reached very rapidly and the vehicle burn tests were ended by manually applying fire suppression agents (water or foam).

In the tests, measurements were made for the flame spread, surface and gas temperatures, heat flux, pressure, and airflow into and out of the passenger compartment. In addition, concentrations of $\mathrm{CO}, \mathrm{CO}_{2}, \mathrm{CH}_{4}, \mathrm{C}_{2} \mathrm{H}_{4}, \mathrm{C}_{2} \mathrm{H}_{2}, \mathrm{HCN}$, $\mathrm{NO}$ and smoke were measured at a single location between the driver and passenger seats, slightly over the seats. The gas concentrations were measured by FTIR and GC/MS techniques and smoke by the filter paper weighing technique. In the fire plume above the vehicle, measurements were made for the concentrations of $\mathrm{CO}, \mathrm{CO}_{2}$ and smoke and release rates of heat and products were derived from the measurements. $\mathrm{CO}$ and $\mathrm{CO}_{2}$ concentrations were measured by the IR gas analyzers and smoke concentration was determined from the measurement for the optical transmission using soot properties.

\section{RESULTS}

The results from the vehicle burn tests are analyzed in detail in Ref. 1 . Some of the data from Ref. 1 , just before time to untenable/flashover conditions $\left(t_{u, f}\right)$, are listed in Tables 1 and 2. 
Table 1. Times to untenable/flashover conditions, $t_{u, f}$, and concentrations of products just before $\mathrm{t}_{\mathrm{u}, \mathrm{fl}}$ in the passenger compartment [1].

\begin{tabular}{|c|c|c|c|c|c|c|c|c|c|}
\hline \multirow{2}{*}{$\begin{array}{c}\text { Test } \\
\#\end{array}$} & \multirow{2}{*}{$\begin{array}{l}t_{u, f l} \\
\text { (s) }\end{array}$} & \multicolumn{6}{|c|}{ Concentration (ppm) } & & \multirow{2}{*}{$\begin{array}{c}C_{s m} \\
\left(\mathrm{mg} / \mathrm{m}^{3}\right)\end{array}$} \\
\hline & & CO & $\mathrm{CO}_{2}$ & $\mathrm{CH}_{4}$ & $\mathrm{C}_{2} \mathrm{H}_{4}$ & $\mathrm{C}_{2} \mathrm{H}_{2}$ & HCN & NO & \\
\hline \multicolumn{10}{|c|}{ Front Crashed Vehicle, Fires in the Engine Compartment } \\
\hline 1 & 645 & 1,370 & 20,770 & 165 & 230 & 145 & 52 & 25 & - \\
\hline 4 & 950 & 1,100 & 3,500 & 262 & 353 & 281 & 11 & 5 & 67 \\
\hline 7 & 1,620 & 440 & 12,500 & 30 & 45 & 28 & - & 18 & $6,224 * *$ \\
\hline 9 & 780 & 330 & 2,400 & 70 & 50 & 50 & 10 & 14 & - \\
\hline 10 & $390^{*}$ & 1,000 & 3,200 & 350 & 550 & 450 & 27 & 6 & - \\
\hline 10 & 780 & 100 & 400 & 100 & 100 & 80 & 8 & 3 & - \\
\hline \multicolumn{10}{|c|}{ Rear Crashed Vehicles, Fires Started Under the Vehicle in the Rear } \\
\hline 2 & 210 & 4,244 & 122,500 & 602 & 784 & 827 & 103 & 66 & - \\
\hline 3 & 199 & 4,797 & 123,100 & 464 & 2,221 & 2,198 & 64 & 48 & - \\
\hline 5 & 170 & 2,500 & 40,000 & 400 & 800 & 500 & - & 10 & 1,548 \\
\hline 6 & 250 & 1,600 & 38,000 & 300 & 470 & 450 & 40 & 30 & 1,350 \\
\hline 8 & 155 & 1,600 & 10,000 & 230 & 350 & 240 & 15 & 5 & 428 \\
\hline 11 & 300 & 7,500 & 205,000 & 650 & 1,550 & 2,600 & 300 & 90 & - \\
\hline
\end{tabular}

*: peak before the untenable/flashover conditions are reached; **: $C_{s m}$ value appears to be too high; -: not measured. or not available.

Table 2. Times to untenable/flashover conditions, $\mathrm{t}_{\mathrm{u}, \mathrm{fl}}$, and concentrations and release rates of heat and products in the fire plume just before $t_{u, f l}[1]$.

\begin{tabular}{|c|c|c|c|c|c|c|c|c|c|}
\hline \multirow{2}{*}{$\begin{array}{c}\text { Test } \\
\#\end{array}$} & \multirow{2}{*}{$t_{u, f l}(s)$} & \multicolumn{2}{|c|}{$C_{j}(\mathrm{ppm})$} & \multirow{2}{*}{$\begin{array}{c}C_{s m} \\
\left(\mathrm{mg} / \mathrm{m}^{3}\right)\end{array}$} & \multirow{2}{*}{$\begin{array}{c}\dot{Q}_{c h} \\
\text { (MW) }\end{array}$} & \multicolumn{3}{|c|}{$G_{i}(\mathrm{~g} / \mathrm{s})$} & \multirow{2}{*}{$\begin{array}{c}V_{\text {fire }} \\
(\mathrm{kW} / \mathrm{s})\end{array}$} \\
\hline & & $C_{C O}$ & $C_{\mathrm{CO} 2}$ & & & $G_{\mathrm{CO} 2}$ & $G_{C O}$ & $G_{s m}$ & \\
\hline \multicolumn{10}{|c|}{ Front Crashed Vehicles, Fires Started in the Engine Compartment } \\
\hline 1 & 645 & 41 & 2,831 & - & 1.25 & 93 & 0.99 & - & 8 \\
\hline 4 & 950 & 32 & 1,512 & 19 & 0.89 & 66 & 0.85 & 0.45 & 10 \\
\hline 7 & 1,620 & - & 1,316 & 43 & 1.13 & 84 & - & 1.20 & 4 \\
\hline 9 & 780 & 34 & 2,874 & 49 & 1.05 & 131 & 1.73 & 1.30 & 9 \\
\hline 10 & 780 & 31 & 1,870 & 16 & 1.23 & 92 & 0.96 & 0.46 & 9 \\
\hline \multicolumn{10}{|c|}{ Rear Crashed Vehicles, Fires Started Under the Vehicle in the Reat } \\
\hline 2 & 210 & 109 & 2,927 & 45 & 1.89 & 139 & 3.23 & 1.12 & 20 \\
\hline 3 & 199 & 45 & 1,776 & 24 & 0.98 & 63 & 1.20 & 0.55 & 14 \\
\hline 5 & 170 & 87 & 2,407 & 27 & 1.19 & 88 & 2.31 & 0.88 & 8 \\
\hline 6 & 250 & 50 & 513 & 28 & 0.60 & 44 & 1.55 & 0.54 & 6 \\
\hline 8 & 155 & 59 & $\begin{array}{l}1,377 \\
\end{array}$ & 13 & 0.91 & 67 & 1.70 & 0.34 & 11 \\
\hline 11 & 300 & 83 & 544 & 26 & 0.36 & 25 & 2.50 & 0.72 & 6 \\
\hline
\end{tabular}

-: not measured or unavailable

\section{Fire Growth Process}

Figure 2 shows plots of heat release rate versus the post ignition time $\left(t_{p i}\right)$ for two tests with front and rear ignitions.

In test \#1 with front ignition, following were observed: 1) $270 \mathrm{~s}$ : section of windshield fell on top of the instrument panel; 2) 360 to $420 \mathrm{~s}$ : instrument panel ignited and flames started to spread; 3) 420 to $480 \mathrm{~s}$ : several vehicle parts in the passenger compartment ignited; 4) 540 to $630 \mathrm{~s}$ : vapors in the engine compartment ignited and flame vented out of the compartment; 5) 645 to 660: flashover was imminent.

In test \#2 with ignition of gasoline pool under the vehicle in the rear, following were observed: 1) 80 to $120 \mathrm{~s}$ : flames entered the passenger compartment and ignited one of the seats; 3) 150 s: several vehicle parts inside the passenger compartment ignited; 4) 170 
to $180 \mathrm{~s}$ : flames started spreading inside the passenger compartment; 5) $210 \mathrm{~s}$ : untenable/flashover conditions were imminent.

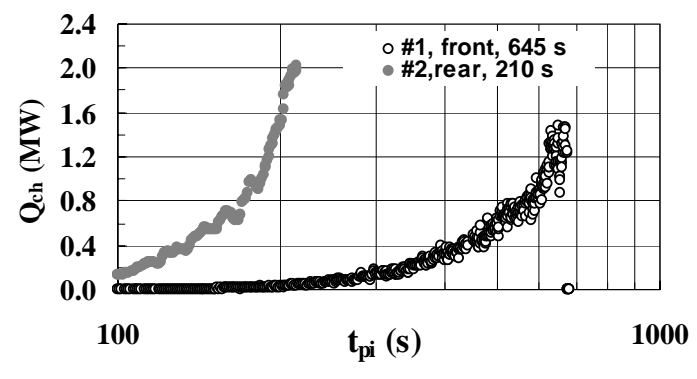

Fig. 2. Heat release rate profiles in the fire plume. $t_{u, f}$ values are included in the legend.

Data in Fig. 2 show that major difference between the front and rear ignition is in the time for flames to enter the passenger compartment. Once the flame spread process starts in the passenger compartment, fire growth in both cases becomes rapid and untenable/flashover conditions reach rapidly. Values for the time to untenable/flashover $\left(t_{u, f l}\right)$, heat release rates and fire growth rates $\left(V_{\text {fire }}\right)$ just before $t_{u, f l}$ are listed in Tables 1 and $2 . V_{\text {fire }}$ values in the table are obtained from the heat release rate profiles just before $t_{u, f l}$.

The $t_{u, f l}$ values are between 645 to $1620 \mathrm{~s}$ for the front crashed vehicle tests and are longer and than the values between 155 to $300 \mathrm{~s}$ for the rear crashed vehicle tests. This difference is due to the times taken by flames to enter the passenger compartment, which are about 4 to 5 times longer for the front crashed vehicle tests than the times for the rear crashed vehicle tests. In the front crashed vehicle tests, flames entered the passenger compartment through the openings in the windshield, HVAC units and some service units. In the rear crashed vehicle tests, flames entered the passenger compartment from the underbody of the vehicle through service openings and openings created by the vehicle crash.

For the front and rear crashed vehicle burn tests, $\dot{Q}_{c h}$ values just before $t_{u, f l}$ are similar and vary between 0.89 to $1.89 \mathrm{MW}$, except for test \#6 (0.60 MW) and test \#11 (0.36 MW; in this test the underbody of the vehicle was protected from heat from the gasoline pool fire by intumescent paint). The similarity of the $\dot{Q}_{c h}$ values indicate that once the flames reach the passenger compartment, both front and rear crashed vehicle tests become similar. The $V_{\text {fire }}$ values in Table 2, just before $\mathrm{t}_{\mathrm{u}, \mathrm{fl}}$ also indicate similarity between the front and rear crashed vehicle tests after flame enter the passenger compartment. The $V_{\text {fire }}$ values vary between 6 to $11 \mathrm{~kW} / \mathrm{s}$, except for test \#2 (20 kW/s), \#3 (14 kW/s) and \#7 (4 kW/s).

These results indicate that it is possible to enhance the survivability of the passengers in the vehicle crash fires by the modifications of vehicle parts to resist flame penetration into the passenger compartment. One of the tests (\#11) did demonstrate that undercoating the vehicle by intumescent paint was somewhat beneficial as it increased the $t_{u, f l}$ value to 300 seconds, which was the highest amongst the rear crashed vehicle burn tests. 


\section{Ratio of the Generation Rate of Products to Heat Release Rate}

Equation 3 suggests that $\dot{G}_{j} / \dot{Q}_{c h}$ ratio, which for fuel-lean conditions depends only on the $y_{j} / \Delta H_{c h}$ ratio, is conserved. This is shown in Fig. 3 for the $y_{s m} / \Delta H_{c h}$ ratio. The ratio is highest for PVC (halogenated fuel), increases with $\Phi$ and reaches a constant value even for fuel-lean conditions. The ratio for PS (aromatic fuel) is less than the ratio for PVC, but is higher than the ratio for the aliphatic fuels. Amongst the aliphatic fuels, the ratio is higher for nylon compared to PP, PE, PMMA, and wood. For both aromatic and aliphatic fuels, the ratio increases slowly with changes to fuel-rich conditions up to $\Phi \approx 1.5$ and then rapidly beyond that value.

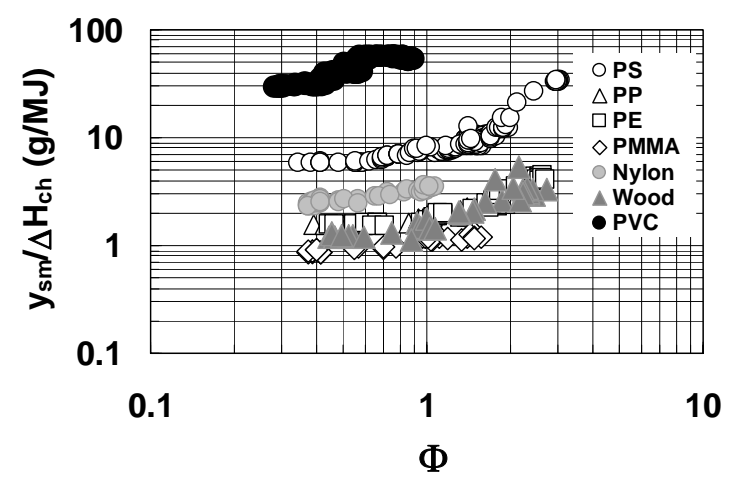

Fig. 3. Ratio of smoke yield to chemical heat of combustion versus the equivalence ratio [2].

For the vehicle burn tests, data in Table 2, just before $\mathrm{t}_{\mathrm{u}, \mathrm{fl}}$, show that the $\dot{G}_{s m} / \dot{Q}_{c h}$ values $\leq$ 1.2 (except for \#11). These values are similar to those in Fig. 3 that are close to the stoichiometric condition for aliphatic fuels. Thus, in vehicle burn tests, vehicle parts and fluids burn predominantly like aliphatic fuels and just before $t_{u, f}$, conditions are close to stoichiometric combustion.

\section{Concentrations of Products in the Passenger Compartment and in the Fire Plume}

The concentrations of products in the passenger compartment were measured at a single location between the driver and passenger seats, slightly over the top of the seats. Figure 4 shows an example of the measured data for test \#2.

Fire growth for this test is described in Section 3.1. There is rapid increase in the concentrations of products as flames enter the passenger compartment (80 to $120 \mathrm{~s}$ and ignition of one of the seats). Formation of HCN starts at about $120 \mathrm{~s}$ and its concentration increases with time, supporting the observation of ignition and burning of polyurethane based seat. A similar behavior is observed in the $\mathrm{CO}$ and $\mathrm{CO}_{2}$ concentration profiles in the fire plume.

The concentration ratios are directly proportional to release rate ratios as indicated by Eq. 4. The relative magnitudes of the concentrations or release rates of products provide information about the combustion behavior of the fuels in terms of fuel-rich or fuel-lean conditions and the generic nature of burning fuels. 


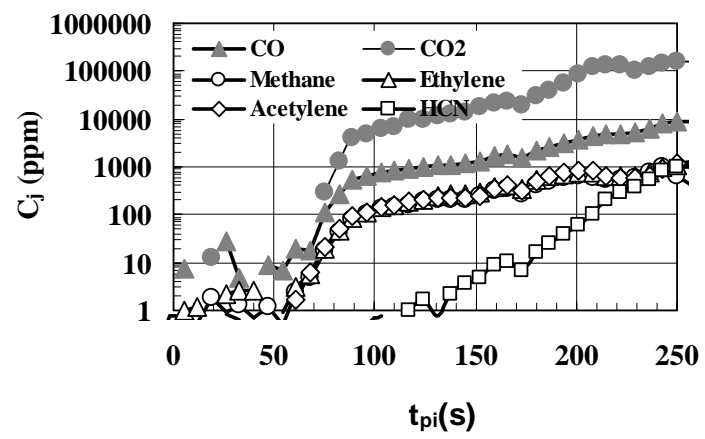

Fig. 4. Concentration profiles of products in the passenger compartment for test \#2.

\section{Product Concentration Ratios}

The concentration ratios provide information as to the mode of combustion and extent of involvement of fuels having atoms such as nitrogen in addition to carbon and hydrogen atoms in the structure.

$C_{\mathrm{CO}} / C_{\mathrm{CO} 2}$ Ratio

The $C_{\mathrm{CO}} / C_{\mathrm{CO} 2}$ ratio is commonly used to examine the combustion behavior of fuels, such as in Fig. 5. The dependency of the $C_{\mathrm{CO}} / C_{\mathrm{CO} 2}$ ratio on the generic nature of fuels is similar to that of the $y_{s m} / \Delta H_{c h}$ ratio, shown in Fig. 3.

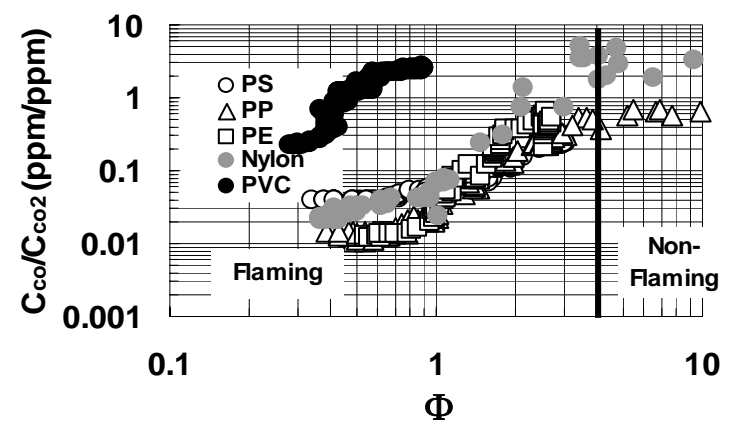

Fig. 5. Ratio of $\mathrm{CO}$ to $\mathrm{CO}_{2}$ concentration ratios versus the equivalence ratio [2].

Under the fuel-lean conditions, $C_{\mathrm{CO}} / C_{\mathrm{CO} 2}$ ratio is highest for PVC (halogenated fuel), followed by PS (aromatic fuel) and nylon, PE, and PP (aliphatic fuel) in that order. For fuel-rich conditions, the ratio for aliphatic fuels becomes higher than for the aromatic fuel (highest for nylon comparable to PVC).

The $C_{\mathrm{CO}} / C_{\mathrm{CO} 2}$ ratio for the vehicle burn tests is shown in Fig. 6 for a front crashed vehicle burn test (test \#1) and a rear crashed vehicle burn test (\#3). Based on the data for the aliphatic hydrocarbon fuels in Fig. 5, the vehicle burn data in Fig. 6 suggest the following: 
1) Test \#1: fuel-rich conditions in the passenger compartment and fuel-lean conditions in the fire plume;

2) Test \#3: fuel-rich conditions in both passenger compartment and fire plume; and

3) close to stoichiometric combustion conditions in the passenger compartment and in the plume just before untenable/flashover for both the tests.

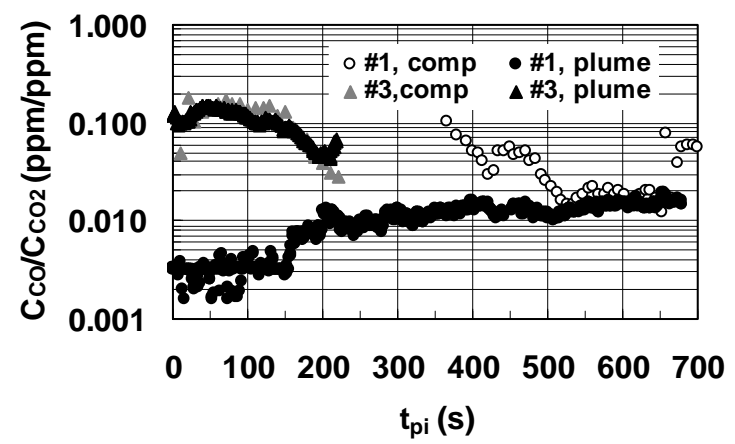

Fig. 6. Ratio of $\mathrm{CO}$ to $\mathrm{CO}_{2}$ concentration ratio profiles in the passenger compartment (comp) and the fire plume for front crashed (\#1) and rear crashed (\#3) vehicle burn tests.

The $C_{\mathrm{CO}} / C_{\mathrm{CO} 2}$ ratios in Tables 1 and 2, just before $t_{u, f \text {, }}$ are also similar to the ratios that are closer to the stoichiometric combustion conditions for aliphatic fuels in Fig. 6. Under these conditions, gas temperatures are higher and thus there is a higher possibility of burn injuries to passengers relative to the injuries due to toxicity and lethality, a conclusion similar to that derived from the estimations for times to pain, $2^{\text {nd }}$ and $3^{\text {rd }}$ degree burns, flashover, toxicity, and lethality [1].

\section{$C_{s m} / C_{C O}$ and $C_{H C N} / C_{C O}$ Ratios}

$\mathrm{CO}$, smoke, and HCN are some of the major products of incomplete combustion that are responsible for toxic hazards. $\mathrm{CO}$ is generated from the partial oxidation of fuel pyrolyzate. Smoke, which is a mixture of soot and organic compounds, is generated from the partial oxidation and further decomposition of the fuel pyrolyzate. Sometimes, smoke is mixed with oxidized inorganic compounds from fuel additives. The ratio of soot to organic compounds depends on the generic nature of the fuel, oxygen concentration, and reaction zone temperature. With increase in the oxygen concentration and reaction zone temperature, ratio of soot to organic compounds increases. In addition, the ratio increases as nature of chemical bonds in the fuel changes from aromatic and unsaturated to aliphatic and saturated bonds. HCN, on the other hand is released from fuels with nitrogen atoms in the chemical structure. The $C_{s m} / C_{C O}$ and $C_{H C N} / C_{C O}$ ratios thus provide relative tendencies of fuel for the release of $\mathrm{CO}$, smoke, and HCN.

The $C_{s m} / C_{C O}$ and $C_{H C N} / C_{C O}$ ratios are shown in Fig. 7, where data are taken from Ref. 2 (and references therein) and in Table 3, where data are taken from Ref.3. The $C_{H C N} / C_{C O}$ ratios in the table are from the calculated concentrations using a chemical kinetic model for the formation of HCN from a mixture of methylamine and ethylene, following a stationary flamelet concept [3]. The experimental $C_{H C N} / C_{C O}$ ratios in Table 3 are from the concentrations measured in the combustion of nylon-6,6 in the ISO 9705 room with 0.89$\mathrm{m}$ and 0.56-m high openings [3]. 
In Fig. 7, the $C_{s m} / C_{C O}$ ratio is about $3 \mathrm{~g} / \mathrm{g}$ for all the fuels included in the figure for the fuel-lean combustion conditions. For PS, an aromatic fuel, the ratio remains approximately constant (between about 2 and $3 \mathrm{~g} / \mathrm{g}$ ) in the fuel-lean as well as fuel-rich combustion conditions. For PVC, a halogenated fuel and other aliphatic fuels, the $C_{s m} / C_{C O}$ ratio decreases as combustion conditions change from fuel-lean to fuel-rich. These results suggest that as soot has an aromatic structure, conversion of aromatic fuel pyrolyzate to soot probably involves significantly less reaction steps compared to those for the aliphatic and halogenated fuels

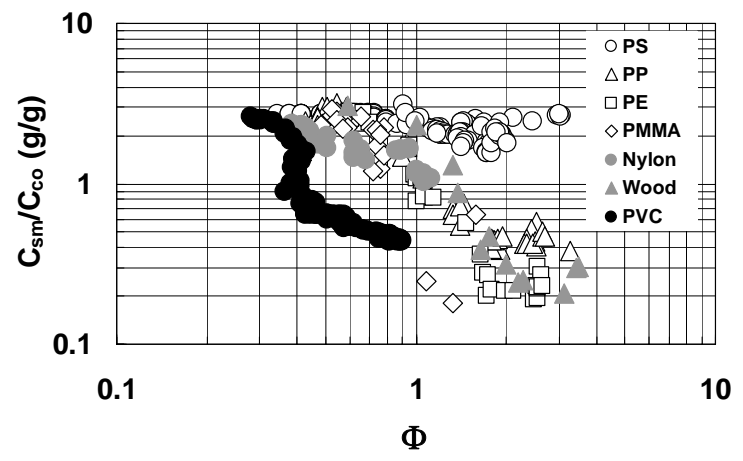

Fig. 7. Ratio of smoke to $\mathrm{CO}$ concentration ratios versus the equivalence ratio [2].

Table 3. Calculated and measured concentration ratios of HCN to CO in the ISO 9705 Room [3].

\begin{tabular}{|c|c|c|c|c|}
\hline \multirow{2}{*}{$\begin{array}{l}\text { Opening Height } \\
\text { (m) }\end{array}$} & \multirow{2}{*}{$\Phi$} & \multirow{2}{*}{ Ventilation } & \multicolumn{2}{|c|}{$C_{H C N} / C_{C O}(\mathrm{ppm} / \mathrm{ppm})$} \\
\hline & & & Calculated & Measured \\
\hline \multirow{6}{*}{0.89} & 0.43 & Non-vitiated & 0.014 & \\
\hline & 0.43 & Non-vitiated & 0.014 & \\
\hline & 0.52 & Vitiated & 0.037 & \\
\hline & 0.55 & & & 0.080 \\
\hline & 0.55 & & & 0.076 \\
\hline & 0.65 & Vitiated & 0.037 & \\
\hline \multirow{4}{*}{0.56} & 0.70 & & & 0.279 \\
\hline & 0.75 & & & 0.282 \\
\hline & 0.94 & & 0.106 & \\
\hline & 0.94 & & 0.119 & \\
\hline
\end{tabular}

For the vehicle burn tests, the $C_{s m} / C_{C O}$ ratios in the passenger compartment and in the plume in Tables 1 and 2 (just before $t_{u, f}$ ) are similar to values in Fig. 7 that are closer to the stoichiometric combustion for aliphatic fuels.

An examination of the $C_{H C N} / C_{C O}$ ratio in Table 3 shows that the ratio increases from a value of 0.014 (for the mixture of methylamine, which is a nitrogen containing fuel, and ethylene, which is a non-nitrogen fuel) to a value as high as 0.282 for nylon-6,6 (only nitrogen containing fuel), as the conditions change from fuel-lean to close to stoichiometric combustion. The $C_{H C N} / C_{C O}$ ratios for the vehicle burn tests, listed in Table 1 , however, are lower than the ratios in Table 3, as nitrogen containing as well as nonnitrogen containing fuels are involved. 
The $C_{H C N} / C_{C O}$ ratio can be used to estimate the relative contribution of nitrogen containing fuels in the vehicle burn tests. For example, in test \#1, instrument panel constructed of ABS (a nitrogen containing fuel) was involved in the fire, in test \#2, polyurethane seat (a nitrogen containing fuel) was involved, whereas in test \#11, nitrogen containing intumescent paint applied to underbody of the vehicle was exposed to flames from gasoline pool fires. For these tests, the $C_{H C N} / C_{C O}$ ratios are $0.038,0.024$, and 0.040 respectively in Table 1 . The $C_{H C N} / C_{C O}$ ratio is 0.080 in test $\# 10$ with FR-HVAC, which is the highest ratio in the table.

\section{SUMMARY}

1. Untenable/flashover conditions are reached earlier in the rear crashed vehicle fires than the front crashed vehicle fires, primarily due to delay in the flame penetration into the passenger compartment;

2. Conditions in the passenger compartment and in the fire plume are closer to the stoichiometric combustion conditions just before untenable/flashover, suggesting higher probability of burn injuries to passengers relative to the injuries due to toxicity and lethality in agreement with the times calculated from the burn and toxic hazard models and flashover times;

3. Under fuel-lean conditions, the mass of smoke is three times the mass of CO. In the vehicle burn tests, where predominantly aliphatic fuels are involved, the smoke to CO mass ratio is about 0.4 for conditions that are closer to stoichiometric combustion conditions;

4. In vehicle fires, the HCN concentration is about $3 \%$ the CO concentration in the passenger compartment; and

5. The analysis of the data measured in the vehicle fires suggests that it is possible to model vehicle fires to assess survivability of passengers through modifications to the vehicles and their polymer parts.

\section{ACKNOWLEDGEMENTS}

Continued encouragements and technical support from Dr. K. H. Digges and Dr. R.R. Stephenson of the Motor Vehicle Fire Research Institute (MVFRI) are gratefully acknowledged. We are thankful to MVFRI for the financial support.

\section{REFERENCES}

[1] Tewarson, A., Quintiere, J., and Purser, D., "Comprehensive Analyses of Post Collision Motor Vehicle Fires,” Technical Report, 3018009, FM Global, Norwood, MA, Charlottesville, VA (to be issued, 2005).

[2] Tewarson, A., "Generation of Heat and Chemical Compounds in Fires," Section 3, Chapter 3-4, The SFPE Handbook of Fire Protection Engineering, Third Edition, National Fire Protection Association Press, Quincy, MA, pp. 3-82 to 3-161, 2002.

[3] Tuovinen, H., Blomqvist, P, and Saric, F., "Modeling of Hydrogen Cyanide Formation in Room Fires,” Fire Safety Journal, 39:737-755, (2004). 